\title{
O tratamento dos estrangeirismos nas duas últimas edições do Dicionário da Língua Portuguesa, da Porto Editora
}

\author{
Ana Rebello de Andrade \\ ILTEC/ FCT/ISEC
}

António Lavouras Lopes ISCE/ESC. Sec. Vitorino Nemésio

\section{INTRODUÇÃO}

É cada vez mais frequente encontrarem-se na imprensa, em publicações mais perenes e na comunicação oral, os chamados estrangeirismos.

A sua entrada veloz cria problemas de ordem linguística -a língua não dispõe do tempo necessário à sua assimilação- e cria, também algumas dificuldades de comunicação.

É um facto que, por necessidade ou por moda, o léxico do português conta com um alargamento de unidades estrangeiras que não pode ser iludido ou ignorado. Antes carece de uma atitude de política linguística frontal e despreconceituada.

1 ILTEC (Investigadora /Direcção do Instituto de Linguística Teórica e Computacional); FCT (Bolseira de Doutoramento da Fundação para a Ciência e Tecnologia, ref. ${ }^{a}$ SFRH/BD7544272001), ISEC (Prof. ${ }^{a}$ Adjunta do Instituto Superior de Educação e Ciências)

2 UNL (Doutorando da Universidade Nova de Lisboa), ISCE (Prof. Adjunto no Instituto Superior de Ciências Educativas), Prof. do Quadro da Escola Secundária Vitorino Nemésio.

Ana Rebello de Andrade y António Lavouras Lopes, "O tratamento dos estrangeirismos nas duas últimas edições do Dicionário da Língua Portuguesa, da Porto Editora", Revista de Lexicografia, IX (2002-2003), pp. 7-28. 
Os estrangeirismos, no que respeita ao seu uso e integração na língua, constituem uma questão antiga mas hoje mais premente do que nunca devido à sua proliferação.

Cabe aos linguistas portugueses a tarefa de os registar, tentar normalizar e integrar no léxico do português. Cabe, também, aos dicionários de língua portuguesa a sua difusão.

Neste artigo pretende-se, num primeiro momento, reflectir sobre a atitude dos mais conhecidos dicionários gerais de língua portuguesa face aos estrangeirismos para, num segundo momento, se proceder à análise do tratamento lexicográfico destes nas duas últimas edições do Dicionário de Língua Portuguesa da Porto Editora (de agora em diante $D L P$ ).

A escolha das duas últimas edições $\left(7^{\mathrm{a}}\right.$ e $\left.8^{\mathrm{a}}\right)$ do $D L P$ para análise fundamenta-se no facto de este ser o dicionário português mais conhecido e mais usado e, por isso mesmo, ter uma maior responsabilidade na forma como reflecte o fenómeno dos estrangeirismos e como informa e forma os seus consulentes. Acresce dizer que este dicionário tem tido um uso escolar alargado, o que faz aumentar a responsabilidade da sua função pedagógica. A análise simultânea de duas edições do mesmo dicionário tem como objectivo revelar a atitude deste, ou melhor, dos lexicógrafos responsáveis pela sua actualização, face à dimensão mais dinâmica da língua que é o léxico, e muito particularmente, na actualidade, em relação ao enriquecimento deste através da importação lexical.

O carácter formativo do $D L P$ tem ainda um maior alcance, já que tem sido o dicionário aconselhado nas escolas, nos escritórios e nos gabinetes de trabalho.

Teria sido interessante abordar a problemática do tratamento dos estrangeirismos no Dicionário da Língua Portuguesa Contemporânea, (conhecido como o Dicionário da Academia das Ciências) e publicado em Abril de 2001 pela Verbo. Essa reflexão irá ser deixada para mais tarde, na sequência daquela que, hoje, aqui se faz, a propósito daquele que era, até há bem pouco tempo, o principal dicionário de referência do português $-\mathrm{o} D L P$. 
A metodologia utilizada nesta análise baseou-se numa recolha sistemática dos estrangeirismos presentes nas várias edições do $D L P$ com o fim de elaborar um corpus de estrangeirismos que, acrescido de recolhas paralelas noutros dicionários gerais de língua e na imprensa, pudesse contribuir, de forma significativa, para traçar um retrato fidedigno do tratamento lexicográfico dos estrangeirismos no português europeu. Esta recolha sistemática foi fruto de vários anos de trabalho tendo sido elaborada por António Lavouras Lopes aquando da sua prestação como colaborador na equipa que elaborou o Dicionário da Lingua Portuguesa Contemporânea (Academia das Ciências).

Antes, ainda, de se entrar na análise do estrangeirismo enquanto objecto lexicográfico reflictamos, ainda que brevemente, sobre a própria noção de estrangeirismo no seio de um fenómeno complexo que é o empréstimo linguístico externo.

Entende-se neste contexto por empréstimo linguístico a passagem de elementos (morfemas, lexias, regências, acepções) de uma língua A para uma língua $B$. De facto, a própria natureza evolutiva da língua e o contacto natural e inevitável que se estabelece entre as várias línguas ocasiona a importação de palavras estrangeiras, consequência de uma adequação linguística ao mundo extralinguístico (cf. Cabré 1995: 40).

A palavra estrangeira ao assumir um papel comunicativo no seio de uma língua que não é a sua originária, passa por uma panóplia de fases, mais ou menos morosas, até à sua completa integração no léxico alheio ${ }^{3}$.

A primeira dessas fases corresponde ao estrangeirismo, cujo tratamento no $D L P$ irá ser alvo de análise neste artigo. $\mathrm{O}$ estrangeirismo designa, deste modo, a fase pela qual passa uma palavra de um léxico de uma língua estrangeira, usada em português, em que algumas das suas características de origem foram desvirtuadas, nomeadamente a nível fonológico (os fonemas inexistentes em português foram substituí-

3 Para uma análise mais detalhada das fases de instalação do estrangeirismo veja-se Andrade e Lopes 1998. 
dos por fonemas existentes nesta língua), a nível morfológico (começam a ser atribuídas as marcas flexionais de género e número de acordo com as regras do português) e a nível gráfico (nota-se uma hesitação na forma de grafar a palavra que se regista ora entre aspas, ora em itálico, ora em negrito, ora a redondo como as palavras indígenas). É de notar que a nível ortográfico se mantém como no léxico de origem (ex.: flirt, leasing, rally).

\section{PANORAMA SUMÁRIO DO TRATAMENTO DOS ESTRANGEIRISMOS NOS DICIONÁRIOS PORTUGUESES}

A lexicografia não se pode alhear do estrangeirismo, sobretudo na lexicografia geral, se se trata de uma unidade corrente e de uso geral. O empréstimo linguístico tem constituído, ao longo da história do português, um importante meio de enriquecimento e alargamento do léxico. Com maior ou com menor relutância, os dicionários acabam por reconhecer o vocábulo importado e fixar-lhe uma forma fonológica e ortográfica. Até esse momento, a palavra é acolhida pelos lexicógrafos, em regime de excepção, numa secção própria do dicionário ou no corpo deste, devidamente assinalada, numa espécie de "antecâmara de naturalização".

Consultando os dicionários gerais da língua portuguesa (editados em Portugal) disponíveis nas livrarias nas últimas décadas do século $\mathrm{XX}$, verificamos que praticamente todos levam em conta a questão dos estrangeirismos ${ }^{4}$. Interessa, entretanto, saber como o fazem. Destacaremos dois grupos distintos: os dicionários vindos do século XIX, que não foram revistos nem actualizados depois de 1960, e os de elaboração ou revisão posterior a esta data.

4 Não se levaram aqui, em consideração os dicionários brasileiros, entre os quais teríamos a realçar o Ferreira (1999). 
A -

Morais - Silva, António de Morais (1949-1959): Grande Dicionário da Língua Portuguesa, 10 a ed. , 12vols., Lisboa, Confluência (1 ${ }^{\mathrm{a}}$ ed. : 1789).

Caldas Aulete - Aulete, J. F. Caldas (1952): Dicionário Contemporâneo da Língua Portuguesa, $3^{\mathrm{a}}$ ed. , 2 vols, Lisboa, Parceria António Maria Pereira (1 ${ }^{\mathrm{a}}$ ed.: 1881$)$.

Cândido de Figueiredo - FigueIREDo, Cândido (1981): Grande Dicionário da Língua Portuguesa, 16 a ed. , 2 vols., Lisboa, Livraria Bertrand ( $1^{\text {a }}$ ed. : 1899) .

No segundo grupo, assinalamos três subgrupos ${ }^{6}$ :

B -

BI

Pedro Machado - Machado, José Pedro (1989): Grande Dicionário da Língua Portuguesa, 2 vols., Lisboa, Euro-Formação ( $1^{\text {a }}$ ed.: 1960-1971).

Lexicoteca - (1985): Lexicoteca - Moderno Dicionário da Língua Portuguesa, 2 vols., Lisboa, Círculo de Leitores.

Lexilello - (1989): Lexilello - Novo Dicionário da Língua Portuguesa, 5 vols., Porto, Lello Editores.

B2

Porto Editora - Costa, J. Almeida, e A. Sampaio Melo (1994 e 1998): Dicionário da Língua Portuguesa, $7^{\mathrm{a}}$ e $8^{\mathrm{a}}$ eds., Porto, Porto Editora (1 $1^{\mathrm{a}}$ ed.: s.d. [1952]).

5 Não se considerou para este efeito, a última edição revista $\left(25^{\mathrm{a}}\right)$, de Cândido de Figueiredo, por se tratar de uma edição polémica.

6 Deixou-se de fora desta análise o Dicionário da Língua Portuguesa Contemporânea, da Academia das Ciências, nas suas duas edições de 1793 e 1979, ambas apenas da letra "A". Considerou-se, entretanto, a edição de 2001, esta para todas as letras. 
Universal - (1995): Dicionário Universal da Língua Portuguesa, Lisboa, Texto Editora.

Novo Lello - (1996): Novo Dicionário da Língua Portuguesa, Porto, Lello Editores.

\section{B3}

Academia - Academia das CiênCIAS de Lisboa (2001): Dicionário da Língua Portuguesa Contemporânea, 2 vols., Lisboa, Editorial Verbo.

Dos dicionários do primeiro grupo (A), o de Caldas Aulete e o de Cândido de Figueiredo tratam os estrangeirismos com alguma timidez (o primeiro mais do que o segundo), dando guarida, no corpo do dicionário, a um número reduzido destes; o terceiro, o de Morais, encara o problema mais frontalmente, dedicando-lhe uma secção final ("Vocabulário de Frases Latinas e Estrangeiras") e conferindo, ainda, a alguns o estatuto de entrada no corpo do dicionário.

Em B.1. temos um conjunto de dicionários recentes com características semelhantes, quanto ao elevado número de estrangeirismos registados e quanto à sua integração na nomenclatura (no corpo do dicionário). As entradas dos estrangeirismos surgem nestes dicionários assinaladas de forma diferente: em Pedro Machado, em itálico; no Lexicoteca, com um asterisco; no Lexilello, sem qualquer indicação tipográfica.

Em B. 2. temos os dicionários de edição recente, mais compactos (em um só volume), com estrutura, quanto à integração dos estrangeirismos, semelhante: um anexo próprio, anunciado na introdução, e várias unidades estrangeiras no corpo do dicionário.

O tão esperado Dicionário da Língua Portuguesa Contemporânea, publicado em Abril de 2001, destaca-se aqui (B.3.) de todos os outros pela sua modernidade. É no âmbito do tratamento dos estrangeirismos que o seu carácter normalizador mais se faz notar. Comprova-o a polémica surgida na imprensa, nos meses seguintes à sua publicação, sobretudo, quanto a alguns dos aportuguesamentos adoptados. 
O referido dicionário regista todos os estrangeirismos no corpo do dicionário, sem marca tipográfica, com tratamento próximo do dispensado às palavras vernáculas.

Este e outros aspectos inovadores do dicionário merecem uma reflexão oportuna que, em breve, prometemos fazer.

\section{VISITA AO INTERIOR DE UM DICIONÁRIO}

$\mathrm{Na}$ impossibilidade, imposta pela dimensão deste trabalho, de fazer uma análise de todos os dicionários, vamos centrar a nossa atenção em apenas um, do segundo grupo, o mais conhecido e mais usado -o DLP. Trata-se de um dicionário essencialmente prático e funcional, num único volume, estruturando os seus artigos de uma forma classicamente tripartida -entrada, classificação gramatical e definição semântica. As definições, geralmente breves e sintéticas, sem exemplos e sem abonações, assentam na grande parte dos casos uma inter-relação sinonímica. Exceptuam-se os termos científicos e técnicos mais modernos, que são definidos de uma forma mais analítica e explícita.

\subsection{OS CORPOS ESTRANHOS DA MACROESTRUTURA}

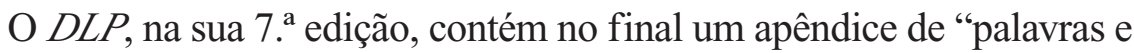
locuções estrangeiras usadas na linguagem escrita e na linguagem falada". Na 8. a edição o mesmo apêndice é designado de "palavras e expressões estrangeiras". Esta arrumação e classificação conferem o mesmo estatuto aos estrangeirismos provenientes das línguas modernas e aos latinismos. Ao mesmo tempo, a nomenclatura do corpo do dicionário surge mesclada de vocábulos estrangeiros. Trata-se de unidades repetidas, ou seja, que surgem também no apêndice. Não se vislumbra a razão da dupla entrada em alguns casos. Aliás, os critérios seguidos no tratamento lexicográfico por este dicionário são omissos. O referido apêndice não é precedido de quaisquer considerações de carácter explicativo. A própria introdução da 7. a edição ("Nota da Editora"), que dedica apenas um parágrafo a esta matéria, refere somente: "Também o apêndice relativo a locuções estrangeiras, usadas com frequência na linguagem escrita e na 
linguagem falada, foi enriquecido, embora cautelosamente, de novas entradas, agora acompanhadas de transcrição fonética [...] ". Ficamos a saber que podem ser encontrados estrangeirismos no apêndice e no corpo do dicionário, mas ignoramos qual o critério que presidiu a essa distribuição. A mesma " Nota da Editora", na 8. . edição, agora muito mais breve, não faz qualquer alusão aos estrangeirismos, nomeadamente às alterações desta vez introduzidas, ao contrário do que era de esperar.

A análise a que a seguir procedemos aplica-se às duas edições, tomando-se, num primeiro momento, como base a $7 .^{\text {a }}$ edição e realçando-se as inovações da $8{ }^{a}$ nesta matéria.

O apêndice da 7. edição é de "palavras e locuções estrangeiras", mas na nota introdutória são anunciadas apenas "locuções estrangeiras". Vejamos, desde já, onde é que está a classificação correcta, ou seja, que tipo de unidades lexicais estrangeiras tem, de facto, entrada no apêndice. Nas folhas azuis (cor das folhas do apêndice), as três primeiras entradas pertencentes a línguas modernas são:

\section{1. abat-jour;}

\section{2. a bocca chiusa;}

\section{3. abondance de biens ne nuit pas.}

Temos em 1., 2., e 3., respectivamente uma palavra composta, uma locução adverbial e uma frase. A nota introdutória anuncia apenas locuções (como em 2.), esquecendo unidades como em 1. e 3. O apêndice, por seu turno, intitula-se de palavras e locuções (como em 1. e 2.). Em nenhum sítio se prevêem as fraseologias (como em 3.) e que também são registadas.

A falta de rigor na classificação das unidades estrangeiras da macroestrutura é uma primeira indicação do estatuto menor atribuído aos estrangeirismos.

A distribuição das unidades lexicais estrangeiras pelo apêndice e pelo corpo do dicionário parece, à primeira vista, ter obedecido a um critério não explicitado, mas aparentemente lógico e pertinente: da nomenclatura do corpo do dicionário farão parte os estrangeirismos que 
são termos científicos de uso internacional; do apêndice, os restantes. Consideremos, de entre esses termos científicos, as unidades de medida. Tomemos como exemplo:

\section{4. kelvin, Watt; \\ 5. parsec, volt; \\ 6. bit, byte;}

7. gigabyte, megabyte;

8. gray, sievert, var.

Os termos em 4. têm duas entradas, no apêndice e no corpo do dicionário, tal como se reproduz:

\section{Corpo do dicionário}

Kelvin, $s$. $m$. unidade de temperatura termodinâmica do S.I., de símbolo K, que equivale $1 / 273,16$ da temperatura termodinâmica do ponto triplo da água.

Watt, s. m. unidade de potência do Sistema internacional, de símbolo $\mathrm{W}$, que é a potência de um agente produtor de trabalho (ou energia) que produz um joule em cada segundo m.9
Apêndice

Kelvin, pal. ing. usada como s. m., (fis) unidade de temperatura termodinâmica do S.I.

Watt, pal. ing. Usada como s. m., (fis.) unidade de potência do S.I.

A dupla entrada pode ser entendida como uma repetição desnecessária, mas também pode considerar-se um expediente didáctico: tratando-se de termos internacionais, não poderiam deixar de figurar no corpo do dicionário; ao mesmo tempo, sendo palavras estrangeiras, seria lógica a sua inclusão também no apêndice. Aqui bastaria então o registo do termo, com remissão para o corpo do dicionário, onde surgiria a definição. Contudo, assim não sucede: surgem duas definições, sendo a do apêndice mais breve. Mesmo assim, a preocupação didáctica poderia ainda estar subjacente, já que uma primeira informação definitória é apresentada no apêndice. De qualquer modo, a remissão para a definição mais alargada seria aconselhável, o que não acontece. 
Esta ordenação aparentemente lógica não assenta num critério geral e uniforme. Um outro grupo de unidades de medida, de que são exemplos as indicadas em 5., não é objecto de igual tratamento. Parsec e volt surgem apenas no corpo do dicionário. $\mathrm{O}$ consulente que encontrou watt no apêndice e, na falta de remissão, se deu por satisfeito com a breve definição disponível, aí procurará também volt e não encontrará, porque este tem entrada apenas no corpo do dicionário.

Entretanto, se o consulente se aperceber de que os termos deste tipo vêm no corpo do dicionário definidos de forma desenvolvida, procurará aí unidades como as de 6. e não as encontrará. É que bit, tal como byte, tem entrada apenas no apêndice. Assim sucede na 7. ${ }^{\mathrm{a}}$ edição. A 8. a já reproduz os artigos destas duas unidades no corpo do dicionário.

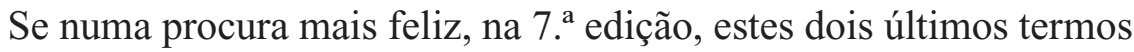
são encontrados, o mesmo já não sucederá com os seus múltiplos - gigabyte e megabyte-, que de todo estão ausentes da nomenclatura. Ausência que se mantém na 8. . $^{\text {edição. }}$

Por fim, termos como os de 8. -gray, sievert, var-, exactamente com o mesmo estatuto de 4., também estão ausentes do apêndice e do corpo do dicionário.

Face a esta amostragem, é fácil concluir que, para cada caso, em vez de um critério de tratamento lexicográfico, o que existe é a sua ausência. A incoerência resultante, tanto a nível da macroestrutura como da microestrutura, espelha bem a menor atenção dada, na concepção do dicionário, aos estrangeirismos.

Esta incoerência na organização da nomenclatura não se circunscreve aos termos técnicos e científicos. Aliás, são estes os tratados com maior rigor. Vejamos alguns exemplos de uso mais generalizado:

\section{9. apartheid, jazz, kimono, sikh;}

\section{0. hardware, kart, know-how, software.}

Não obstante a existência de um apêndice destinado aos estrangeirismos, os vocábulos de 9. não constam desse anexo. Surgem apenas no corpo do dicionário. Interessaria saber porquê. 
Em 10. temos quatro estrangeirismos que, por seu turno, têm duplo registo -no apêndice e no corpo do dicionário-, assim tratados:

\section{Corpo do dicionário}

Hardware, s. m. (inform.) designação que engloba todos os elementos da aparelhagem e acessórios que fazem parte de um computador (teclado, visor, impressora, etc.). (Pal. Ing., de hard, "duro; rijo" + ware , "artigos; objectos; material").

Kart, $s$. $m$. pequeno veículo automóvel de competição, de um só lugar, com embraiagem automática, sem carroçaria nem suspensão (Pal. anglo-americana).

Know-how, s. $m$. o saber fazer; conhecimento prático (de modo especial nos domínios da técnica e do comércio). (Do ing. to know, "saber" + how, "como").

Software, $s . m$. (inform.) conjunto de programas e de rotinas indispensáveis ao funcionamento do computador e de todo o restante hardware.(Do ing. software, de soft, "mole" + ware, "artigos; objectos; material")

\section{Apêndice}

Hardware., pal. ing. usada como s. m., (inform.) designação que engloba todos os elementos da aparelhagem e os acessórios que fazem parte do sistema do computador (teclado, visor, impressora, etc.) . (De hard, , "duro; rijo" + ware, "artigos; objectos; material").

Kart, pal. anglo-americana usada como s. m. (desp.) pequeno veículo automóvel de competição, de um só lugar.

Know-how, expressão inglesa usada como s.m. (com.) conhecimento técnico; experiência; prática; o que saber fazer. (Do verbo to know, "saber" + how, "como").

Software, pal. ing. usada como s. m. (inform.) conjunto de meios não materiais (em oposição a hardware) que servem para o tratamento automático da informação e permitem o "diálogo" entre o homem e o computador; conjunto de programas que possibilita o funcionamento do computador no tratamento do problema que lhe é posto.

Não se sabe qual o critério utilizado no tratamento destes estrangeirismos. Hardware e software, como termos técnicos do domínio da informática, poderiam merecer um tratamento especial -dupla entrada-, como os termos (alguns) da metrologia já vistos. Mas para os outros dois -kart e know how - não será válida esta razão, dado o seu uso mais corrente. Além disso, a repetição deveria ter uma função didáctica, através da remissão o que não sucede. Por outro lado, coerente- 
mente, entradas da mesma natureza deveriam obter igual tratamento, o que também não acontece. Consideremos hardware e software: o primeiro é objecto de duas definições sensivelmente iguais; o segundo na 7. ${ }^{\mathrm{a}}$ edição, tem definições diferentes (a mais desenvolvida no apêndice), reproduzida esta pela $8 .^{a}$ edição no corpo do dicionário. Kart beneficia igualmente de duas definições (neste caso a mais desenvolvida é a do corpo do dicionário). Quanto a know-how, igualmente com duas entradas, os respectivos artigos têm estrutura e conteúdo distintos, como se pode ver. A 8. ${ }^{a}$ edição introduz a marca neol. $\mathrm{Na}$ definição de software, no corpo do dicionário, não fazendo o mesmo na definição do apêndice. No resto, em tudo igual. É estranha esta marca redundante de neol. No artigo de um estrangeirismo, que, aliás, não é usada por sistema.

Estes critérios cruzados, ou a sua ausência, não nos permitem entender a relação existente entre o apêndice e o corpo do dicionário, ou seja, a articulação entre o propósito linguístico, a técnica lexicográfica e o sentido pedagógico da integração dos estrangeirismos.

\subsection{A ACTUALIZAÇAO CAUTELOSA DA ENTRADA DE ESTRANGEIRISMOS NO DICCIONARIO}

$\mathrm{Na}$ “ Nota da Editora” da 7. a edição diz-se que o apêndice dos estrangeirismos foi enriquecido, embora "cautelosamente", de novas entradas. Traduzindo enriquecimento por actualização (embora cautelosa), esperar-se-ia encontrar nas páginas desta nova edição um conjunto de vocábulos estrangeiros de uso alargado no momento da sua publicação (1994). Entretanto isso não sucede. Consideremos os seguintes casos:

\section{1. full-time, jeans, lobby, part-time;}

\section{2. pop, skinhead, surf, vison.}

As unidades de 12. não foram levadas em conta pela macroestrutura da 7. ${ }^{\mathrm{a}}$ edição. Terão estes quatro estrangeirismos sido cautelosamente omitidos em nome da defesa da língua, por não terem um carácter funcional imprescindível? 
Pertencerão à classe dos que têm apenas um valor conotativo, ou seja, serão, apenas, marcas emblemáticas da cultura anglo-americana e veículo da sua influência?7 De facto, são dispensáveis no quadro de referência do português, dispondo o léxico, para essas realidades, de designações vernáculas: tempo inteiro ou integral, calças de ganga, grupo de pressão, tempo parcial. Mesmo assim, porque se trata de estrangeirismos frequentes, seria função do dicionário registá-los e indicar os correspondentes vernáculos. Este expediente lexicográfico de indicação da sua dispensabilidade no léxico do português -apenas peregrinos de visita breve ${ }^{8}$. Entretanto a nova edição $\left(8^{\mathrm{a}}\right)$, quatro anos depois, parece ter tomado consciência dessa lacuna: regista full-time no apêndice e lobby e part-time no corpo do dicionário, continuando jeans esquecido.

Não se compreende, entretanto, o critério de distribuição, nomeadamente quanto a full-time e part-time, de estatuto tão igual e tratamento tão díspar.

E como justificar a ausência das unidades assinaladas em 12? São estrangeirismos de uso frequente e não têm o mesmo grau de disponibilidade dos de 11. Pop e $\operatorname{surf}$ (este último finalmente registado na $8 .^{a}$ edição) expressam conceitos sem tradução linguística em português, ou seja, nenhuma unidade do léxico se disponibilizou ainda para acolher o seu significado. Não existe, até agora, nenhuma outra forma de referir esse tipo de música ( $p o p$ ) e essa modalidade desportiva (surf). A exclusão destas duas unidades da nomenclatura do dicionário dificilmente encontrará uma justificação de carácter lexicográfico, já que uma das formas de ampliação dos meios de referência da realidade é a importação lexical, quando os recursos produtivos internos não respondem às novas necessidades comunicativas. Neste momento pop e surf são unidades funcionais do vocabulário de muitos falantes, e a sua omissão no dicionário não lhes retira a funcionalidade.

7 Cf. Guilbert (1975: 91).

8 Cf. Guilbert (1975: 92 e segs.). 
O significado de skinhead (ou forma abreviada de skin) -igualmente uma realidade nova- não foi absorvido por nenhum vernáculo. Entretanto, tem vindo a surgir, a par do estrangeirismo, a sua tradução ou decalque em cabeça-rapada que este dicionário também não regista. Trata-se de formas actualmente concorrentes na designação de uma (parcela da) realidade, de que o $D L P$ não dá conta.

Quanto a vison, forma estrangeira para uma realidade que não é nova, o seu aportuguesamento em visom ou visão está consagrado pelo uso, mas este dicionário ignora-o. Excluindo da macroestrutura tanto o estrangeirismo como o seu aportuguesamento, o dicionário ignora também esta parte da realidade.

\subsection{A INFORMAÇAO FORNECIDA PELO DICIONÁRIO SOBRE A} LEXICALIZAÇÃO DE ALGUNS ESTRANGEIRISMOS

Da lista do apêndice fazem parte algumas lexias que foram há muito objecto de integração lexical, por via do aportuguesamento, ou seja, por adaptação dos significantes ao sistema fonológico (também morfológico e sintáctico, em alguns casos) e ortográfico do português. Estes neologismos, surgidos por importação, quando funcionais e de uso alargado, não podem deixar de fazer parte da nomenclatura do dicionário geral da língua. Ao mesmo tempo, justificar-se-á também o registo das formas de origem, isto é, dos estrangeirismos, quando se trata de pares concorrentes com valor de uso. Mais, ao dicionário competirá dar conta, de forma explícita, dessa concorrência. Casos destes surgem no DLP, mas não tratados exactamente desta forma. Vejamos os seguintes exemplos:

\section{3. bar, carpete, leader;}

\section{4. kiwi, nuance, whisky.}

As unidades de 13. têm entrada no apêndice, onde são definidas, sem qualquer indicação das formas aportuguesadas -bar, carpete, líder. O utilizador do apêndice é esclarecido sobre o sentido destes estrangeirismos, mas não lhe é facultada uma outra informação importante -que estas palavras estrangeiras têm já formas portuguesas, tendo por esse 
motivo, atingido um grau de lexicalização avançado na língua. E, no entanto, estas últimas surgem no corpo do dicionário. Trata-se de uma duplicação de definições (não exactamente iguais) de interesse questionável, faltando o elemento articulador fundamental, que é a remissão, como se pode verificar:

\section{Corpo do dicionário}

bar, $s . m$. anglicismo vulgarizado para significar a dependência de hotel, restaurante, estabelecimento ou casa particular, onde se servem bebidas alcóolicas; móvel onde se guardam estas bebidas, nas casas particulares. (Do ing. bar, "bar; botequim")

carpete, $s$. f. tapete grande. (Do fr. carpete, "id").

Líder, s. m. (angl.) chefe; orientador; indíviduo que chefia uma empresa, uma corrente de opinião ou um grupo; representante de uma bancada parlamentar; Agremiação ou atleta que ocupa o primeiro lugar em qualquer competição desportiva. (Do ing. Leader, "chefe").
Apêndice

bar, pal. ing. usada como s. m., dependência de hotel, restaurante ou casa particular onde se servem bebidas; móvel onde se guardam bebidas.

Carpette, pal. fr. usada como s. f., tapete grande para sala, quarto, etc...

Leader, pal. ing. usada como s. m., aquele que guia ou dirige; chefe; caudilho. (Emprega-se modernamente esta palavra para designar o chefe de um partido político).

Nestes casos, em que a concorrência se desvanece a favor das formas adaptadas, o princípio da economia poderia desaconselhar a duplicação de artigos. Os aportuguesamentos são de tal forma vulgares, que qualquer consulente os procurará de imediato no corpo do dicionário. Podemos admitir, entretanto, razões de ordem lexicográfica -manter presente o acervo de unidades estrangeiras do português contemporâneo. Mas, neste caso, o elenco de estrangeirismos registados deveria incluir muitas outras unidades ausentes, e o princípio da remissão para as formas aportuguesadas não deveria ser esquecido. A 8 a edição manteve esta situação, apesar de se notar uma reflexão sobre estas unidades, nomeadamente líder, de que foi retirada a marca angl. e carpette, 
a cuja definição acrescentou "tapete estreito e comprido", criando, neste caso, um desequilíbrio ainda maior entre a definição do estrangeirismo e a do empréstimo.

Este tipo de articulação, ou desarticulação, entre o apêndice e o corpo do dicionário é ainda evidenciado pelas unidades de 14. Kiwi e qui$v i$ no corpo do dicionário constitui uma das poucas excepções, mas está erradamente localizado. O apêndice, que deveria ter essa função, tem neste caso um papel redundante e marginal. As próprias definições repetidas que aí surgem, com estrutura e conteúdos distintos, revelam que se trata de um dicionário à parte dentro do próprio dicionário.

Nuance, na 7. edição, vem registado no apêndice e contém na definição o próprio aportuguesamento (nuança), como se pode ver, sem, no entanto, remeter para ele. Trata-se de um indício de diálogo frustrado, já que no corpo do dicionário o neologismo de importação nuança (ou nuance) não tem entrada:

Corpo do dicionário

Apêndice

Nuance, pal. fr. usada como s. f., nuança; tonalidade; gradação de cor; cambiante; aspecto

Neste último caso, a $8 .^{a}$ edição introduz alterações estruturais: alusão ao aportuguesamento deixa de ser feita, e o estrangeirismo tem agora dupla entrada, com a mesma definição semântica.

Em último lugar, temos whisky, que na 7. a edição surge no apêndice e no corpo do dicionário. Em definições breves e iguais, é remetido para o seu aportuguesamento -uísque-, como se vê:

\section{Corpo do dicionário}

Whisky, $s . m$. espécie de aguardente de cereais; o m. que uisque. (Do ing. Whisky ou whiskey, "id")

\section{Apêndice}

whisky, pal. ingl. usada como s. m., espécie de aguardente de cereais; o. m. q. uísque. 
Temos, finalmente, o tratamento lexicográfico reclamado: a forma estrangeira, embora repetida, com a remissão para o respectivo aportuguesamento, que virá, obviamente, como cabeça de artigo, no corpo do dicionário. Mas, também aqui, a dinâmica da neologia de importação, de que o dicionário deve dar conta, é traída -em vão o consulente procurará uísque, porque não consta da nomenclatura do dicionário, na 7. ${ }^{\mathrm{a}}$ edição. A $8^{\mathrm{a}}$ edição, entretanto, corrige esta situação. Mantém as duas entradas de whisky, com remissão para uisque, surgindo este finalmente como cabeça de artigo, com a mesma definição do estrangeirismo.

\subsection{A DiNÁMICA DA NEOLOGÍA DE IMPORTAÇÃO NO DICIONÁRIO}

De edição para edição, o $D L P$ tem-se revelado atento ao número de estrangeirismos em uso. A 8. ${ }^{a}$ edição introduz algumas alterações que reflectem essa atenção.

Quanto à organização da nomenclatura, o caso whisky é exemplar: com dupla entrada -apêndice e corpo do dicionário, com remissão para o respectivo aportuguesamento- e tripla definição. O conceito "espécie de aguardente de cereais" surge assim três vezes no dicionário, o que denota uma preocupação de não deixar o consulente privado da informação procurada.

Confrontando o apêndice das duas edições que vêm sendo analisadas, não são perceptíveis diferenças sensíveis. Estas notam-se mais no corpo do dicionário. Neste, a $8 .^{a}$ edição dispensa um maior acolhimento aos estrangeirismos, nomeadamente aos mais vulgarizados, independentemente do registo ou não do respectivo aportuguesamento. Este facto parece indicar um reconhecimento mais desinibido das unidades lexicais estrangeiros. Assim se verifica, entre outros, com dandy, dossier, feedback, flashback, flirt, forcing, gaffe, holding, leasing, marketing, rally, robot, rugby, stand, stress, etc.

Todas estas unidades surgem na $8 .^{a}$ edição simultaneamente no apêndice e no corpo do dicionário, enquanto na $7 .^{a}$ edição vêm atestados apenas no apêndice. As respectivas definições, em duplicado, em geral são iguais, como sucede com whisky, mas há exepções, sem se entender porquê, como dandy, feedback e robot. Dandy aparece no 
apêndice, definido através de um único vocábulo (“janota") e sem remissão para o aportuguesamento (dândi), e no corpo do dicionário, aqui sem definição, mas com remissão para dândi, este por sua vez definido de forma analítica ("homem que veste com extremo apuro; janota"). Robot vem nos dois sítios com a mesma definição, sem indicação do seu aportuguesamento (robô), que, entretanto, lá se encontra na ordem alfabética, com definição ligeiramente diferente. Feedback tem duas entradas, nas definições distintas, mal se reconhecendo nelas o mesmo conceito.

Constata-se que, nesta última edição do dicionário, os critérios de tratamento dos estrangeirismos continuam incertos. A própria dominante enunciada -a repetição do estrangeirismo- é bastante frágil: não se compreende por que razão deverão ter tratamento diferenciado unidades como boom, cachet, chance, chauffage, dancing, dealer, fair play, freelancer, lifting e tantos outros de uso igualmente alargado, que têm direito a figurar apenas no anexo. E que dizer de estrangeirismos como aftershave, air bag, best-seller, blues, cartoon, gang, hippy, jackpot, etc., que não têm nenhuma distinção aparente dos dois grupos anteriores e figuram, tal como os vernáculos, exclusivamente no corpo do dicionário? É incompreensível a lógica de tratamentos tão diferenciados.

A 7. a edição do $D L P$ ignorava estrangeirismos de uso inquestionável como estes últimos. A sua introdução agora, na $8 .^{a}$ edição, directamente no corpo do dicionário, sem terem passado pelo apêndice, revela afinal uma preocupação exagerada que seria desculpável se, à semelhança da edição anterior, não continuasse a considerar inexistentes palavras estrangeiras não menos importantes, como affaire, barman, blazer, bowling, bunker, bypass, capot, collant, crash, cross, etc.

Não obstante as incoerências e lacunas já apontadas, é visível, na última edição, a preocupação em valorizar a presença dos estrangeirismos no léxico do português. Um último dado que abona em favor dessa tendência é a forma tipográfica das entradas. $\mathrm{Na} \mathrm{7.a}$ edição, as unidades estrangeiras cabeça de artigo surgiam em itálico; na $8{ }^{a}$ edição sem qualquer indicação ou justificação prévias, apresentam-se 
em redondo, não se distinguindo dos vernáculos. Uma medida igualitária que significa reconhecimento de cidadania? Geralmente, só a transcrição fonética das unidades estrangeiras permite distingui-las das nacionais. São poucas as que vêm acompanhadas da marca da língua a que pertencem ( $p a l$. ing, por exemplo). Mas existem casos em que não é possível distinguir o estrangeiro do vernáculo, porque alguns não têm a indicação da pronúncia de origem. É o caso de surf, ausente da $7 .{ }^{\mathrm{a}}$ edição e presente na $8 .^{a}$ (só no corpo do dicionário), que coloca o consulente perante um dilema: o léxico do português é composto por palavras portuguesas e inglesas, indistintamente, ou aquela palavra inglesa considera-se assim mesmo, com terminação em - $\mathrm{f}$ (final de palavra estranho à fonologia do português), aportuguesada? Em igual situação se encontra flirt. E ainda, aftershave e jackpot, com sequências gráficas inexistentes em português. E como reagir perante disco-jockey, um corpo híbrido (ing. disc.jockey), que vem só na 8 . $^{\mathrm{a}}$ edição e apenas no corpo do dicionário e de que nem sequer é indicada a etimologia?

Os critérios de adaptação dos estrangeirismos ao sistema lexical do português, seguidos pelo $D L P$ proporcionariam outro extenso conjunto de reflexões. Fica para uma próxima oportunidade.

\section{CONCLUSÃO}

O $D L P$ é, dos dicionários portugueses, um dos que têm maior tradição no tratamento dos estrangeirismos. A inclusão de um anexo com palavras estrangeiras só encontra precedente no Morais (neste desde a 8. ${ }^{a}$ edição). De entre os dicionários do seu género, foi o primeiro a dar elevada atenção às palavras estrangeiras com funcionalidade no léxico da língua. Entretanto, a forma de que essa atenção se reveste é denunciadora da insegurança com que a lexicografia lida com a importação lexical.

A passagem brusca do purismo dominante na primeira metade do século XX para o permissivismo e a ausência de reflexão teórica sobre o fenómeno dos estrangeirismos permitem compreender as hesitações, omissões, sobreposições, em suma os titubeios no tratamento 
de um fenómeno antigo, mas com dimensões novas, patentes não apenas no dicionário analisado, mas na generalidade dos dicionários portugueses.

$\mathrm{Na}$ ausência de uma política nacional da língua no domínio da importação lexical, o dicionário oscila entre a não-repressão e a nãosanção, uma solução construída pela negativa, que, obviamente, não pode ser positiva, já que ilude o que urge encarar com frontalidade.

A interpenetração linguística, uma consequência inevitável da era das telecomunicações, é um factor de desenvolvimento das sociedades, mas pode afectar a identidade cultural e a estrutura das línguas dos países que são mais receptores do que doadores, se os fluxos não forem adequada e actualizadamente acompanhados e regulados. Os dicionários não podem descurar esta preocupação, hoje com maior acuidade, porque os estrangeirismos, devido ao seu elevado número e ao ritmo de entrada, já não passam pela lenta, mas sábia, oficina do povo, onde, genuinamente, a língua se faz e refaz.

\section{BIBLIOGRAFÍA}

\section{DICIONÁRIOS GERAIS}

ACAdemia das Ciencias de LIDBOA (2001): Dicionário da Língua Portuguesa Contemporânea, 2 vols., Lisboa, Editorial Verbo.

Aulete, J. F. Caldas. (1952): Dicionário Contemporâneo da Língua Portuguesa, $3^{\mathrm{a}}$ ed., 2 vols., Lisboa, Parceria António Maria Pereira (1 ${ }^{\mathrm{a}}$ ed.: 1881).

Costa, J. Almeida e A. Sampaio Melo (1994 e 1998): Dicionário da Língua Portuguesa, 7. ${ }^{\mathrm{a}}$ e $8 .^{\mathrm{a}}$ eds., Porto, Porto Editora ( $1^{\mathrm{a}}$ ed.: s.d. [1952]).

Ferreira, Aurélio Buarque da Holanda (1999): Novo Dicionário da Língua Portuguesa, $3 .^{\mathrm{a}}$ ed., Rio de Janeiro, Nova Fronteira ( $1^{\mathrm{a}}$ ed.: 1975).

FigueIredo, Cândido (1981 e 1999): Grande Dicionário da Língua Portuguesa, 16. ${ }^{\mathrm{a}}$ e $25 .^{\mathrm{a}}$ eds., 2 vols., Lisboa, Livraria Bertrand (1. ${ }^{\mathrm{a}}$ ed.: 1899). 
Machado, José Pedro (1989): Grande Dicionário da Lingua Portuguesa, 3. ${ }^{a}$ ed., 13 vols., Lisboa, Euro-Formação (1. ${ }^{\text {a }}$ ed.: 1960-1971).

Silva, António de Morais (1949-1959): Grande Dicionário da Língua Portuguesa, 10. ${ }^{\text {a }}$ ed., 12 vols., Lisboa, Confluência ( $1^{\text {a }}$ ed.: 1789).

Lexicoteca (1985): Lexicoteca - Moderno Dicionário da Língua Portuguesa, 2 vols., Lisboa, Círculo de Leitores.

LeXILELlo (1989): Lexilello - Novo Dicionário da Língua Portuguesa, 2 vols., Lisboa, Círculo de Leitores.

- (1989): Lexilello - Novo Dicionário da Língua Portuguesa, 5 vols., Porto, Lello Editores.

Universal (1995): Dicionário Universal da Língua Portuguesa, Lisboa, Texto Editora

Novo Lello (1996): Novo Dicionário da Língua Portuguesa, Porto, Lello Editores.

\section{DICIONÁRIOS ESPECIALIZADOS}

Machado, José Pedro (1994): Estrangeirismos na Língua Portuguesa, Lisboa, Editorial Notícias.

Costa, F. A. da. (1990): Dicionário de Estrangeirismos, Lisboa, Editorial Domingos Barreira.

Schmidt-Radefelt, Jurgen e Dorothea Schurig (1997): Dicionário dos Anglicismos e Germanismos na Língua Portuguesa, Frankfurt am Main, Verlag Teo Ferrer de Mesquita.

Outras

Alves, Maria Ieda (1995): "Empréstimos nas línguas de especialidade: algumas considerações. Borrowed terms in languages for specific purposes: some considerations", Ciência da Informação, 3/95, vol. 24, pp. 319-321.

ANDRADE, Ana Rebello de (1996): As palavras importadas no léxico da decoração, Dissertação de Mestrado em Linguística Portuguesa Descritiva, apresentada à FLUL, Lisboa, inédita.

— _ e António Lavouras LOPES (1998): "Primeira fase de instalação do estrangeirismo" in Actas do XIII Encontro da Associação Portuguesa de Linguística, Lisboa, APL, vol. I, pp. 77-89.

CABRÉ, María Teresa (1995): "Sobre manleus i diccionaris", in Estudis de Linguística i Filologia offerts a Antoni M. Badia i Margarit, III, Barcelona, Universitat de Barcelona/Publicacions de 1'Abadia de Montserrat, pp. 39-61. 
Humbley, J. (1974): "Vers une typologie de l'emprunt linguistique", Cahiers de Lexicologie, XXV, pp. 46-70.

GUILBERT, Louis (1975): La Creativité Lexicale, Paris, Larousse.

Vilela, Mário (1994): Estudos de Lexicologia do Português, Coimbra, Liv. Almedina. 